\title{
Consciousness and the Public Space: Discovering a Pedagogy
}

\author{
Maxine Greene \\ Teachers College \\ Columbia University
}

There are what Hannah Arendt (borrowing from Brecht) once called "dark times." She meant times when the light that should arise from a public realm is "extinguished by 'credibility gaps' and 'invisible government,' by speech that does not disclose what is but sweeps it under the carpet, by exhortations, moral and otherwise, that, under the pretext of upholding old truths, degrade all truth to meaningless triviality" (1968, p. viii). The same conditions, she said, were described in Sartre's Nausea, where everything there "exists in an opaque, meaningless thereness. ..." And she pointed to signs of similar experiences in Heidegger's Being and Time, particularly where the power of "mere talk" is described, "mere talk" that assaults the authentic and the real. What does this signify for pedagogy in the present day? How can the authentic be secured? How can meaning be restored? How can the. extinguished light be lit again so that teachers and learners can appear before one another and show, in speech and action, who they are and what they can do?

I choose to begin with images, with some notions of what is possible, and with some cautionary words. The images are drawn from works of literature, largely because imaginative literature, unlike documentary material, awakens resonances. The words mean more than they say; and they evoke, in those willing to pay heed, other images, memories, things desired, things lost, things never entirely grasped or understood. I want to recall to you aspects of an intersubjective world, a dangerous and endangered world with respect to which we are choosing ourselves as teachers-one we have somehow to understand and provoke others to understand, one we hope in some fashion to transform.

The first image is of a "noxious cloud," taken from Don Delillo's novel, White Noise (1985). It is an invisible cloud created by the escape of a deadly chemical from a railroad car in an ordinary midwestern college town in the midst of normal life. And it relates, as the adolescent Heinrich says, to "the kind of radiation that surrounds us every day. Your radio, your TV, your microwave oven, your power lines just outside the door, your radar speed-trap on the highwav." He tells his family calmly, "For years they told us these low doses weren't dangerous" (p. 174). What do people do in relation to the nameless, the odorless, the ubiquitous? What do they do under a weight they can neither interpret nor understand? In this 
case, they go shopping in supermarkets, hunt pills to stave off the fear of death, take refuge in Hitler studies in their preoccupation with what is technicized, computerized, depersonalized. It all ends: "And this is where we wait together, regardless of age, our carts stocked with brightly colored goods. A slowly moving line, satisfying, giving us time to glance at the tabloids in the racks. The tales of the supernatural and the extraterrestrial. The miracle vitamins, the cures for cancer, the remedies for obesity. The cults of the famous and the dead" (p. 326).

Yes, there are attempts to make sense of it-literal sense, technical sense, even semiotic sense, at least of popular culture. But how can one grasp a toxic cloud, described on the radio as a "feathery plume?" How does one grasp a technician's explanation that a "massive data-base tally" has determined one is dead, that one is "the sum-total" of one's data, but that one does not necessarily mean that anything is going to happen "to you as such, at least not today or tomorrow?" How does one integrate the constant presence of men in Milex suits with German shepherds trained to sniff out toxic stuff hidden in the cracks? The men wear masks with hoses attached; one cannot see their faces or read their expressions or know what they know.

The thought of secret knowledge, concealed knowledge summons up for me another image, that of the labyrinthine library in Umberto Eco's The Name of the Rose (1983). It is in a medieval monastery, where monks are being murdered to seal their lips, where windows and manuscripts and cryptograms and sculptures and mirrors and ordinary household objects compose a shifting reality of signs and symbols that can only be deciphered by the liberated mind. The books in the library and the knowledge they contain are controlled, kept secret, possessed. The "hoard of learning" there is not to be put at others' disposal. William, the English monk, who has been ostensibly sent to solve the crimes committed at the abbey, speaks of a "lust for knowledge" characterizing those who guard the labryinth; and he associates it with onanism, because he sees the knowledge being sought for its own sake. It is not difficult, however, to find in that approach to knowledge a metaphor for current mystifications. There are, most probably, no hexagonal rooms in official agencies today, no carved doorways, no stained glass renderings of sealed books and mythological monsters. But, in what Jurgen Habermas calls the "distortions" of context-free communication (1971, p. 164), in the cost-benefit language, the language of instrumental reason by which phenomena are "explained," there exists a deceptive, often indecipherable reality of signs and symbols. The knowledge they represent is not knowledge for its own sake; but it is secret knowledge nonetheless and often dangerous in its implications. Those who guard it, those who possess it are in their own 
fashion lustful; and there is no way of challenging them if we do not know how to read.

And who are "they," those anonymous ones, who have established themselves in control? Another image comes to mind, an older one, taken from Joseph Conrad's Heart of Darkness (1950, pp. 65-158). It is of the three nameless officials - a Director of Companies, a Lawyer, and an Accountant-sitting in a cruising yawl on the Thames, waiting for the tide to turn. A seaman and riverboat pilot named Marlow is trying to tell them about "the dark places" on the earth, about what it is like to confront the wilderness, to live in the midst of the incomprehensible where "the truth is hidden-luckily." $\mathrm{He}$ is trying to explain what conquerors are like, to say something intelligible about the fascination of greed and brute force, "the powerless disgust, the surrender, the hate." And then he tells them (ironically, bitterly), "mind, none of us would feel exactly like this. What saves us is efficiency, the devotion to efficiency" (p. 68). Immersed in their own roles in the power structure, frozen in natural attitudes, the three auditors are incapable of understanding what he is saying; indeed, they try to stop him at various moments in the telling of his story. "You can't understand," cries Marlow. "How could you? With solid pavement under your feet, surrounded by kind neighbors ready to cheer you or to fall on you, stepping delicately between the butcher and the policemen...." He goes on to speak of people who are too dull to notice assaults by the "powers of darkness," of those so "thunderingly exalted" as to be deaf and blind "to anything but heavenly sights and sounds." For most of us, he asserts, "The earth is a place to live in, where we must put up with sights, with sounds, with smells, too, by jove!-breathe dead hippo, so to speak, and not be contaminated" (p. 122).

In some respect, he is drawing attention to the lifeworld which the attitude of his listeners (like that of the "dull" and the "exalted") obscures. Such a world, it must be clear, is not explicable in terms of cause-effect connections; no quantitative measurements can account for what happens. At best, it can become variously and provisionally meaningful from the perspectives of those who inhabit it: ivory-hunters, managers, riverboat pilots, black helmsmen, native women; a girl who believes forever in Kurtz's "greatness-his generous mind"; Kurtz himself, who cries out "The horror! The horror!" before he dies. Of course "the truth is hidden"; but there remains the possibility of meaning and yes, the choice not to be contaminated as we go down the rivers of our lived worlds.

I begin this way in part because I believe that when we "do" the human sciences-phenomenology of childhood, hermeneutics, semiotics, literary criticism-we have to relate ourselves somehow to a so- 
cial world in multiple ways polluted by something invisible and odorless, overhung by what strikes many as a motionless cloud. It is the cloud of givenness, of what is taken to be "natural" by those caught in the taken-for-granted, in the everydayness of things. I think we have to hold in mind the fact that the modern world is an administered world structured by all sorts of official languages. More often than not, they are the languages of domination, entitlement, and power; and there are terrible silences where ordinary human speech ought to be audible, silences our pedagogies ought somehow to repair. It is, as well, a world where what we conceive to be our tradition is either petrified, located in private enclaves, or surrounded by auras that distance it from lived experience, from the landscapes of our lives.

Too few are being enabled to crack the codes, to uncover that in which they are embodied, to appropriate visions and perspectives that are legitimately theirs. We all believe that our efforts to understand the young and recover our own landscapes must be linked to notions of pedagogical praxis. I am sure we agree that the pedagogies we devise ought to provoke a heightened sense of agency in those we teach, empower them to pursue their freedom, and, perhaps, transform to some degree their lived worlds. We may have to reflect more deeply than we have, however, about how we can cherish the integrity of the meanings children make and the intuitions they share while intentionally educating them-or learning along with themto interpret, to cope with the mystified, endangered world. I think we have to take seriously the disclosures and critiques of those who take certain radical social and political views, even as we try in our fashion to break with the frames that falsify what we think of as children's lives. Yes, I think we all want to explore and recover what have been called the secret places. But we ought also to link the secret places to public spaces. I want to try to do in the name of what Paulo Freire calls "humanization" (1970, p. 27ff.) and in the name of what Hannah Arendt called the "common world" (1961, p. 196).

Before going on, I find it necessary to speak about possibility, about what I imagine to be a better order of things. Like Jean-Paul Sartre, I believe that it is only when we have in mind a better order that we can notice the deficiences of what exists. It is a matter of looking at things as if they could be otherwise, of imagining ourselves and those around us existing otherwise. "It is on the day that we can conceive of a different state of affairs," wrote Sartre, "that a new light falls on our troubles and our suffering and that we decide that these are unbearable" (1956, p. 435). When we decide in such a manner and choose to act to end our troubles, we bring values into being. Those who cannot conceive this, who adapt themselves, who acquiesce, do so (according to Sartre) because they lack the "education and reflection" it requires to move towards what is not yet. 
There are no blueprints for a better society or even a better school system. I shall offer some images again, hoping only to move my readers to look for themselves beyond the actual, to play with untapped possibilities. One image that comes to mind is that of men, women, and children in a sunlit garden, as rendered by Alice Walker at the end of The Color Purple (1983). "Why us always have family reunion on July 4th, say Henrietta, mouth poke out ... White people busy celebrating they independence from England July 4th, say Harpo. So most black folks don't have to work. Us can spend the day celebrating each other" (p. 250). Another comes from Ntozake Shange's For Colored Girls who have Considered Suicide When the Rainbow is Enuf (1977). It is made present by the lady in brown, recalling when she ran into the Adult Reading Room when she was not supposed to "\& came across" Toussaint l'Ouverture, the "beginnin uv reality for me" (p. 26). The first is an image of connectedness and family love; the second, of transcendence, of a leap beyond by a child who knew that "pioneer girls \& magic rabbits \& big city white boys" were keeping her in an unbearable place. A third image is also related to a library: It is an image of Virginia Woolf looking for books by women in the British Museum. She reads Trevelyan's History of England to find out what he said about women. When she finishes, she concludes:

Indeed, if woman had no existence save in the fiction written by men, one would imagine her a person of the utmost importance; very various; heroic and mean; splendid and sordid; infinitely beautiful and hideous in the extreme; as great as a man, some think even greater. But this is woman in fiction. In fact, as Professor Trevelyan points out, she was locked up, beaten, and flung around the room. (1957, p. 45)

Might it have not been at that moment that Virginia Woolf decided this was unendurable and moved on to her demand for "a room of one's own?" She read; she reflected; she refused. Sartre would have said that she became educated.

The last image has to do with the reflective too and with the ethical, with a refusal of contamination by someone who has indeed lived in the world. I have in mind Tarrou and Dr. Rieux taking an hour out for friendship from their struggle against the plague in Albert Camus's novel (1948). Tarrou tells Dr. Rieux the story of his life for the first time and explains why he thinks people ought to keep "endless watch on themselves." No one, he says, is free from plague and, in a careless moment, likely to breathe it into someone's else's face and transmit the microbe. For him, the good man who "hardly infects anyone" is the one who has "the fewest lapses of attention." And then: "You see, I'd heard such quantities of argument, which very nearly turned my head, and turned other people's heads enough to make them approve of murder; and I'd come to realize that all our troubles spring from our failure to use plain, clean-cut 
language. So I resolved always to speak-and to act-quite clearly, as this was the only way of setting myself on the right track. That's why I say there are pestilences and there are victims, no more than that. .. . That's why I decided to take, in every predicament, the victims' side, so as to reduce the damage done ..." (p. 230). Taking the "path of sympathy," he tells Rieux, he wants to be "a saint without God." Although it may not be the case that most of our troubles spring from a failure to speak clearly, a choice to link clarity to compassion in a world of doctrines and denials opens a vision of one type of possibility. If plague signifies, among other things, indifference, abstractness, and an acceptance of complicitousness (approving murder, approving humiliations), vigilance is indeed required to combat it. And this may be the vigilance - and care-our pedagogies ought to release.

There are a few cautionary words to be said, however, before attempting to skeich such pedagogies. Certain ones I take from Michel Foucault and his reminder that we share in a widespread cultural consciousness distinctive of western intellectuals and that we cannot help but be in some manner "agents for this system of power" (1977, p. 207). The very idea of our responsibility for "consciousness" and discourse, he said, forms part of the system. Power inheres in our very language, emancipatory though it may appear to be. This comes particularly clear when I ponder the dissonances existing between what some of us hope to do in the schools in the way of critical thinking and imaginative futuring and the demands of a conservative community. Foucault believed that any mode of discourse is bound to raise resistances, even small ones; and, when I think of resistances by fundamentalists and other types of conservatives (frightened and uninformed though they may be), I am thrust into perplexity. It seems evident that this is something we will have to confront and take into account.

Another cautionary word has to do with the social structures that stand in the way of fulfillments - the free play of energies, the wideawakeness, the authenticity, the moral sensitivity I, at least, would like to see. We cannot ignore or set aside the inequities, the indecencies, the pressure of ideologies. Nor can we ignore the unequal transmission of what is called knowledge, the tracking of children, the demeaning of poor and immigrant people's experience, the one-dimensionality of reform proposals, all of which are functions of existing social structures and tendencies. I am not taking a deterministic view nor suggesting that schools inevitably reflect what is happening in the culture outside. I am suggesting, though, that the meanings that emerge in the transactions between schools and the existing socio-economic order tend to have more to do with channeling than with opening opportunities, with constraining than 
with emancipating, with prescribing than with empowering or setting persons free. I am not sanguine about the resistance of teachers to all this, given the nature of bureaucracies and their administration. Nor am I comfortable with the thought of career ladders and the identification of "master teachers" in the days to come. There is a new taken-for-grantedness with respect to meritocracy, hierarchies, and ladders that demands new kinds of critical interpretation, new ways of questioning lived worlds; and it is difficult to predict if a human science orientation will be strong enough to withstand what prevails.

My last cautionary word has to do with the human condition itself, with the experience of absurdity we live through when our deepest existential questions are met with blank silences. It has to do with our mortality, with randomness, with absences, with the emptiness of the sky. I think of Alfred Schutz pointing to the "fundamental anxiety" that he associated with the feeling that our lives are essentially meaningless, that we may walk across the earth and leave no sign that we have ever been alive (1967, p. 247). Out of such anxiety comes the idea of a project, a plan of action. It is by means of making such plans, anticipaling what they involve, and acting consciously upon them that we create our identities in the situations of our lives. Specific human acts, as Sartre put it, cut cross the social milieu while taking its determinations into account; and they transform the world to a degree, not in spite of, but on the basis of given conditions. To have a project is to relate both to existing conditions and to something we are trying to bring into being. It means going beyond the situation; and Sartre said that this is what characterizes the human being fundamentally, that and what that human being succeeds in making out of what he/she has been made (1963, pp. 9293). In some sense, this is a response to what Freud called "civilization and its discontents" (1953), which always suggests a final cautionary word. Who can deny that to be "civilized" is to be to a degree "schooled?" Who can deny that it means (to a degree) giving up the simple pursuit of pleasure, repressing certain desires, sublimating others? One of our shared interests is in finding alternatives to templates and schemata that overwhelm primordial landscapes. Another is in creating a civilization that can tolerate the potency of desire, the thrust of diverse energies, the vitality of play, the intention to transform.

We who are teachers have to strive against limits, consciously to strive. The alternatives are not to be found in a rediscovery of untrammelled subjectivity or in acceptance of total determinism. There is a dialectical relation marking every human situation: the relation between the individual and the environment, the self and society, the living consciousness and the object-world. This relation 
presupposes a mediation between the reflective and material dimensions of lived situations, both of which are equally significant. It is not the kind of tension that can be overcome by a triumph of subjectivity or objectivity; nor is it the kind of dialectic that can finally be resolved. There are always survivals from the past; there are always pressures; there is always a certain weight in the lived situation - a weight due to the environment, to traumas from the past, to experience with exclusion or poverty or the impacts of ideology. We achieve freedom through confrontation with and partial surpassing of such weight or such determinateness. We achieve it, however, only when what presses down (or conditions, or limits) is perceived as an obstacle. When oppression or exploitation or pollution or even pestilence is perceived as "natural" or a "given," there can be no freedom. When people cannot name alternatives, imagine a better state of things, they are likely to remain anchored or submerged.

It is my view that teachers, if they are to develop a humane and liberating pedagogy, must feel themselves to be engaged in such a tension, in such a dialectical relation with what surrounds. They are more likely to uncover or be able to interpret what they are experiencing if they can at times recapture some of their own lost spontaneity, some awareness of their backgrounds, either through communication with children, psychotherapy, or aware engagement with works of art. Anyone may provoke them to recall that rationality is grounded in something pre-rational, pre-reflective-perhaps in a primordial, perceived landscape. When I read Wordsworth, Melville, Elisabeth Bishop, Toni Morrison, when I look at paintings by Cezanne and Van Gogh, I am convinced that this is true. Maurice Merleau-Ponty wrote that "perception is a nascent logos ... it teaches us, outside of dogmatism, the true conditions of objectivity itself ... it summons us to the tasks of knowledge and action" (1964, p. 25). The conditions of objectivity, of course, have to do with the vantage points of the embodied consciousness moving, seeing, touching, hearing in the midst of things. He was not trying to reduce knowledge to sensation. He was trying to recover "the consciousness of rationality" by showing how it begins in the perspectival patternings of situated consciousness, in the lived experience to which the cogito always refers.

As the young move into the life of language, Merleau-Ponty believed, as they begin thematizing and symbolizing their experiences, horizons are breached; the landscape is transformed; experiences are clarified. The prereflective, the perceived become a launching place - the ground of rationality. And, indeed, our presentness to ourselves depends to a large degree upon the capacity to remain in touch with the perceived world in its incompleteness and openness, to think that world, as it were, while keeping our consciousness open to the common, to the culture our ideas cannot but express. It seems 
clear that the three officials in Heart of Darkness are no longer capable (if they ever were) of being present to themselves in such a fashion. Nor is the contemptible Kurtz with his talk of "My Intended, my station, my career, my ideas," his greed for "lying fame, sham distinction . . . all the appearances of success and power" (Conrad, p. 146). Nor are those who are plague-stricken, those who think they can possess knowledge and presume it to be complete. That is why my images of possibility have so much to do with color and shape and motion; it is why they extend to renderings of connection, compassion, and care. It is why incompleteness seems so important, along with the refusal of false finalities, total systems of thought, what is sometimes called "commensurability" (Rorty, 1980, p. 315 ff.).

We need only to go back to children. We know that their perceiving is the initial mode of configuring, of organizing the experience of external events, of orienting the self to the surround. Like imagination, which organizes the imagery (the elves, the unicorns, the adult world not yet seen, the adventures not yet lived), it is a primordial operation underlying the relation between the knowing subject and the object that is known. These modes of ordering lived reality, along with the feelings associated with family and other relationships, have much to do with language learning and the intellectual elaboration of experiences. This surely points to the importance of our freeing children to tell their stories, not only so that we can hear them but so that they can make meaningful the birth of their own rationality. It may remind us, too, of the importance of affirming the validity of many kinds of experiences, even those that seem incompatible with our own interpretations of the world.

Radical critics speak often of the demeaning effects of atmospheres that exclude the lived lives of children who are strangers or impose overlays of information that seem to falsify what such children live and know. Indeed, we are all too familiar with the feeling that many of those we believe we are teaching are simply accommodating us by imitating our languages, memorizing our terminology. Their distancing themselves is not ordinarily a resistance, although it may sometimes seem that way. It is often an expression of childhood alienation or a split in consciousness. This is one of the many reasons why we need to try harder than we usually do to attend as we develop our particular projects and struggle to move beyond. We can learn from those who have learned, in their way, to listen to children and pay heed to what they say and write. We can do more when it comes to the conscious bringing into being of speech situations and free writing situations in which children can find out what they think and why, what they see and how-through talking about it, writing about it, bringing meaning into their worlds. 
Merleau-Ponty spoke of "lived" decentering and of the gradual achievement of reciprocity within the vital order as part of a process by which children can effect, renew and keep restoring their relations with one another and with the persons around. The vital order is treated as a condition in which equilibrium is rhythmically attained with respect to virtual, not existing conditions. The person brings these into existence by going beyond ordinarily accepted limits and constituting a proper milieu for himself/herself (Merleau-Ponty, 1967, pp. 145-146). This, it will be recalled, is what Shange's lady in brown recalls doing as a child when she moved beyond the vital order to a "human order" which involves the production of new conditions, new structures. He believed (as I think most of us do) that what defined the embodied consciousness or the living human being was "the capacity of going beyond created structures in order to create others" $(1967$, p. 175). This has everything to do with the capacity to choose and create varying points of view-beyond the computers and the tabloids and the tales of extraterrestrials. It has to do with perceptual consciousness, with the emergence of a signified and signifying world.

This, to me, is among the crucial concerns of a humane and critical pedagogy. To recognize that things, truths, and values are constituted by human beings, by children as they orient themselves to aspects of their lived worlds, is to begin to ground what we do in classrooms. The idea of a nascent logos suggests to me that children (like us when we were young), perceiving profiles, incompleteness all around, live in a world of constantly shifting perspectives and horizons. Imagining what it is like where the road turns, where their fathers and mothers go in the early mornings, what the indistinct voices are really saying, what the darkness holds, they become gradually conscious of what it means to make connections in experience. They become aware of funding and sedimenting the meanings they accumulate; they find out something about reading the flickering and multiform world. And yes, since theirs is also a dialectic experience, they may feel themselves struggling against the restraints of dependency and pre-given structures, against facticity itself.

Memory and imaginative engagements and reflection on perceived landscapes are not, of course, the only modes of understanding. As we develop our pedagogies, we ought not to exclude what some of the structural and semiotic approaches can tell us. Nor ought we to overlook such comments as those made by Hans-Georg Gadamer when he tried to correct "the peculiar falsehood of modern consciousness: the idolatry of scientific method and of the anonymous authority of the sciences." He called, in that vein, for a concern for understanding rather than a preoccupation with method, and a vindication of the "noblest task of the citizen-decision-making ac- 
cording to one's own responsibility-instead of conceding that task to the expert" (1975, p. 316).

This brings me back to my argument for an intensified effort to break through customary frames to come in closer touch with the consciousness of those we teach. It is an argument stemming from a concern about airborne events-noxious clouds, if you will -and cover-ups and false consciousness and helplessness. It has to do as well with the need to empower the young to deal with the threat and fear of holocaust, to know enough, to understand enough to make significant choices as they grow. Surely, education today must be conceived as a mode of opening the world to critical judgments by the young and to imaginative projections, and, in time, to transforming actions. There are those among us who oppose the so-called "adult-centered" approach, who find it hopelessly permeated with the desire for power of which Foucault spoke. They view that approach as equivalent to the oppressive and would sometimes choose to leave children be. Like critics who appear to put their faith in the untrammelled "natural" creature, once freed from the weight of hegemony, such thinkers seem to believe that the young, in their innocence and creativity, will be able to constitute better and fresher worlds. Such views, for me, evade the reality of the human condition and the challenges of the nuclear age, the age of accident and torture and inequities. We must acknowledge the fixities and corruptions of our technicized, consumerist culture. We must take into account the languages of technique and violence, even as we do the miseducative aspects of much that is done in schools. They are, after all, largely hierarchical, bureaucratic institutions with their own internal demands for perpetuation and equilibrium. By their very nature, they make it extraordinarily difficult for openings to be explored and critical thinking to take place.

But all of us know that interstices can be found in the structures; communities can be created; desires can be released. I still believe that we have to learn how to enable the diverse young to join the culture's "conversation" as it has gone on over time and as it continues on. I think we, in education, have a particular responsibility to renew what is meant by that "conversation," to do what we can to include within it the voices of the long silent ones or the unheard: women's voices, newcomer's voices, Hispanic and Oriental and African and Arab and Indian voices. It may be a matter of opening works in the sciences and humanities as possibilities for individual children and young people, opening them for discoveries and for new perspectives on the common world. We are all familiar with the problematic of what has been called "cultural reproduction" and what Pierre Bourdieu has called "the conversion of economic into symbolic capital" (1977, p. 196). We know the degree to which the transmission of culture can screen out and even deny the contradic- 
tions and negations associated with the economy. But that should call upon us to work for the reappropriation of cultural forms by the diversity of newcomers in our classes-through emphasis on interpretive and critical approaches, through continuing efforts to break through the enclaves and make all sorts of forms accessible to new and unexpected "readings." Recognizing that meanings are not pregiven, that they are to be variously achieved and not simply unearthed, we ought to be able to find new modes of initiating the young into the so-called "provinces of meaning" (Schutz, 1967, p. 231ff.) that allow for many ways of directing attention to the world. To understand how children themselves reach out for meanings, go beyond conventional limits (once the doors are ajar), seek coherence and explanations is to be better able to provoke and release rather than to impose and control.

Young persons have the capacity to construct multiple realities once they have begun to name their worlds. And the naming, quite obviously, is a function of a growing acquaintance with conceptual networks and symbol systems characteristic of the culture's way of making sense. The young can be empowered to view themselves as conscious, reflective namers and speakers if their particular standpoints are acknowledged, if interpretive dialogues are encouraged, if interrogation is kept alive. Idiomatic understandings are always likely; but the constitution, the construction cannot but be in terms of the culture to which the young belong or intend to belong. It becomes all the more important, then, to tap the full range of human intelligences and enable people to have a number of available languages at hand, not verbal or mathematical languages alone. Some may find articulation through imagery; others, through body movement; still others, through musical sound. Mastery of a range of languages is necessary if communication is to take place beyond small enclosures within the culture; without them, it is extremely difficult to chart the lived landscape, to thematize experience over time. Speaking with others, working with others, playing with others, making things with others, the young may be enabled to attain some reciprocity of perspectives as they try to create networks of relationship within and among themselves. I am not talking about moving them into what was once called the "house of intellect." I am not speaking of an attempt to induct them into the social system of intellectuals in a way that separates them from the lived and the shared. Even those who go on to become specialistsphysicists, literary critics, anthropologists-need not lose touch with their own vantage points, their landscapes, their intersubjectively lived worlds.

Nor need they ever overlook the fact that reality must be understood as interpreted experience, and that there can be multiple perspectives and interpretations within a given context and according 
to acknowledged norms. Only through a recognition of this, I think, will the stunned sense of domination by "white noise" be lessened and the screen of distorted communication be pulled aside. For this to happen, teachers themselves must maintain an open and interpretive approach, not merely to subject matter, but to the texts of children's and young people's lives, and to the meanings the young achieve. Clifford Geertz speaks about finding out how others "across the sea or down the corridor, organize their significative world" (1983, p. 154). Perhaps, with this in mind, we should think of children being down the corridor, ordering and accumulating meanings. Geertz reminds us of how much there is to say about "how meaning gets moved, or does not, reasonably intact from one sort of discourse to the text," about intersubjectivity and how separate individuals come to conceive or do not "reasonably similar things; about how thought frames change ... thought norms are maintained, thought models acquired...." Meaning is for the subject, we know that; and meanings are always identified in a field. They are meanings associated with what M.M. Bakhtin called the "heteroglossia" of the culture (1981, p. 273); cognitive meaning and common-sense meanings, yes, but street-fair meanings, theatrical meanings, intimate meanings, folk-sayings, anecdotes, and the rest. Somehow teachers and inquirers might try, with the help of the young, to tap into such heteroglossia even as they try to read the world as it presents itself to a multiplicity of consciousnesses, theirs and those they are trying to reach.

It is not enough to emancipate individuals or to enable them to disclose their lived worlds for their enlightenment and our own. Lifeworlds themselves have to be reflected on critically; in visible contexts they have to be transformed. The culture and its traditions compose part of the context; so do the languages of the present, and the noxious clouds and the hoarded books and the socio-economic phenomena of the world. I hope we can ponder the opening of wider and wider spaces of dialogue, where diverse students and teachers, empowered to speak in their own voices, reflect together as they try to bring into being an "in-between." Not only may they weave what Hannah Arendt called a "web of reflections" among themselves (1958, p. 184) - as embodied consciousnesses, as persons always reaching beyond. They may through their coming together constitute a newly human world, one worthy enough and responsive enough to be both durable and open to continual renewal. Of course this has to begin in local places, in schoolrooms and school yards and neighborhood centers; it has to begin where people know each others' names. But it can reach beyond towards a space where more and more common interests are articulated, an enlarging public space. It can radiate to inform the "conversation" and to empower individuals to open themselves to what they are making in common. Once they are open, once they are informed, once they are engaged 
in speech and action from their many vantage points, they may be able to identify a better state of things-and go on to transform. Sometimes I believe it is our only hope. "And so each venture is a new beginning," wrote T. S. Eliot, "a raid on the inarticulate. ..." And later, "There is only the fight to recover what has been lost/ and found again and lost again and again; and now, under conditions that seem unpropitious. But perhaps neither gain nor loss. For us there is only the trying" (1958, p. 128). Trying, yes, and the pursuit of freedom, and critical understanding, and a transformation (if we are lucky) of lived worlds.

\section{References}

Arendt, H. (1958). The human condition. Chicago: The Chicago University Press.

Arendt, H. (1961). Between past and future. New York: The Viking Press.

Arendt, H. (1968). Men in dark times. New York: Harcourt Brace \& World.

Bakhtin, M. M. (1981). The dialogical imagination. Austin: The University of Texas Press.

Bourdieu, P.P. (1977). Outline of a theory of practice . Cambridge: Cambridge University Press.

Camus, A. (1948). The plague. New York: Alfred A. Knopf.

Conrad, J. (1950). Heart of darkness. New York: Signet Books.

Delillo, D. (1985). White noise. New York: The Viking Press.

Eco, U. (1983). The name of the rose. New York: Harcourt Brace Jovanovich.

Eliot, T. S. (1958). Four Quartets. The collected poems. New York: Harcourt Brace and Company.

Foucault, M. (1977). Intellectuals and power. In D. F. Bouchard (Ed.), Language, counter-memory, practice. Ithaca: Cornell University Press.

Freire, P. (1970). Pedagogy of the oppressed. New York: Herder and Herder.

Freud, S. (1953). Civilization and its discontents. New York: The Hogarth Press.

Gadamer, H. G. (1975). Hermeneutics and social science. Cultural hermeneutics. 2.

Geertz, C. (1983). Local knowledge. New York: Basic Books.

Habermas, J. (1971). Knowledge and human interests. Boston: Beacon Press.

Merleau-Ponty, M. (1964). The primacy of perception. Evanston: Northwestern University Press.

Merleau-Ponty, M. (1967). The structure of behavior. Boston: Beacon Press.

Rorty, R. (1980). Philosophy and the mirror of nature. Princeton: Princeton University Press.

Sartre, J-P. (1956). Being and nothingness. New York: Philosophical Library.

Sartre, J-P. (1963). Search for a method. New York: Alfred A. Knopf.

Schutz, A. (1967). The problem of social reality. Collected Papers I. The Hague: Martinus Nijhoff. 
Shange, N. (1977). For colored girls who have considered suicide when the rainbow is enuf. New York: The Macmillan Company.

Walker, A. (1983). The color purple. New York: Washington Square Press.

Woolf, V. (1957). A room of one's own. New York: Harcourt Brace and Company. 